\title{
Pathophysiology of gastroesophageal reflux disease-which factors are important?
}

\author{
Karl-Hermann Fuchs ${ }^{1}$, Arielle M. Lee ${ }^{1}$, Wolfram Breithaupt ${ }^{2}$, Gabor Varga ${ }^{2}$, Benjamin Babic ${ }^{3}$, \\ Santiago Horgan ${ }^{1}$
}

${ }^{1}$ Department of Surgery, Center for the Future of Surgery, University of California San Diego, La Jolla, CA, USA; ${ }^{2}$ AGAPLESION Markus Krankenhaus, Klinik für Allgemeine und Viszeralchirurgie, Frankfurt am Main, Germany; ${ }^{3}$ Klinik und Poliklinik für Allgemeine-, Viszeral- und Tumorchirurgie, Universitätskliniken Köln, Cologne, Germany

Contributions: (I) Concept and design: KH Fuchs, W Breithaupt, G Varga, B Babic; (II) Administrative support: All authors; (III) Provision of study materials or patients: KH Fuchs, W Breithaupt, G Varga, B Babic; (IV) Collection and assembly of data: KH Fuchs, W Breithaupt, G Varga, B Babic, AM Lee; (V) Data analysis and interpretation: All authors; (VI) Manuscript writing: All authors; (VII) Final approval of manuscript: All authors.

Correspondence to: Prof. Dr. Karl-Hermann Fuchs. Visiting Associate Professor, University of California San Diego, Center for the Future of Surgery, 9500 Gilman Drive, MC 0740, La Jolla, CA 92093, USA. Email: Karl-Hermann.Fuchs@gmx.de.

Background: Pathophysiology of gastroesophageal reflux disease (GERD) shows a multifactorial
background. Different anatomical and functional alterations can be determined such as weakness of the lower
esophageal sphincter (LES), changes in anatomy by a hiatal hernia (HH), an impaired esophageal motility
(IEM), and/or an associated gastric motility problem with either duodeno-gastro-esophageal reflux (DGER)
or delayed gastric emptying (DGE). The purpose of this study is to assess a large GERD-patient population
to quantitatively determine different pathophysiologic factors contributing to the disease.

Methods: For this analysis only patients with documented GERD (pathologic esophageal acid exposure) were selected from a prospectively maintained databank. Investigations: history and physical, body mass index, endoscopy, esophageal manometry, 24 h-pH-monitoring, 24 h-bilirbine-monitoring, radiographicgastric-emptying or scintigraphy, gastrointestinal quality of life index (GIQLI).

Results: In total, 728 patients (420 males; 308 females) were selected for this analysis. Mean age: 49.9 years; mean BMI: $27.2 \mathrm{~kg} / \mathrm{m}^{2}$ (range, 20-45 kg/m²); mean GIQLI of 91 (range: 43-138; normal level: 121); no esophagitis: 30.6\%; minor esophagitis (Savary-Miller type 1 or Los Angeles Grade A): 22.4\%; esophagitis [2-4]/B-D: 36.2\%; Barrett's esophagus 10\%. Presence of pathophysiologic factors: HH 95.4\%; LES-incompetence 88\%, DGER 55\%, obesity 25.6\%, IEM 8.8\%, DGE 6.8\%.

Conclusions: In our evaluation of GERD patients, the most important pathophysiologic components are anatomical alterations (HH), LES-incompetence and DGER.

Keywords: Gastroesophageal reflux disease (GERD); pathophysiology of GERD; lower esophageal sphincter (LES); hiatal hernia; duodeno-gastro-esophageal reflux (DGER)

Received: 29 October 2019; Accepted: 10 February 2020; Published: 25 October 2021.

doi: $10.21037 /$ tgh.2020.02.12

View this article at: http://dx.doi.org/10.21037/tgh.2020.02.12

\section{Introduction}

Numerous publications on the pathophysiology of gastroesophageal reflux disease (GERD) demonstrate the multifactorial background of this benign disorder, highly prevalent in the western industrialized countries of
North America and Europe (1-7). Understanding of the pathophysiology of reflux has expanded in recent decades with the advent of new diagnostic technology (8-15). The disease is associated with reflux of gastric contents into the esophagus causing mainly increased acid exposure in the esophageal lumen and/or esophagitis $(5,14)$. GERD often 
has an inconsistent clinical picture, with many variables contributing to the disease process. Patients present with a wide variety of initial symptoms; the classic manifestations of GERD are heartburn and/or regurgitation. However, patients may demonstrate atypical symptoms as well, presenting with cough, laryngitis, and asthma $(5,6)$.

Morphological and functional investigations may demonstrate the presence of different anatomical and functional alterations such a weakness of the lower esophageal sphincter (LES), an altered frequency of transient LES relaxations (TLESRs), changes in anatomy i.e. the presence and size of a hiatal hernia $(\mathrm{HH})$, and associated motility disorders such an impaired esophageal motility (IEM) and/or the possible involvement of associated gastric motility problems (4-19). Most reports are more focused on one or the other background cause of the disease (10-20). Prior reports on the pathophysiology of GERD often neglect to include a quantitative assessment of a large population, instead focusing on a qualitative overview of pathophysiological factors (5-7). The importance of the individual involvement of pathophysiologic components of GERD may be elucidated by analysing a large population of GERD-patients, thus permitting a broad assessment of the presence of factors contributing to the development of GERD. This opportunity was provided by documenting these factors over years in a tertiary referral center for patients with benign upper gastrointestinal disorders.

Based on publications on the pathophysiology of GERD, in conjunction with several published guidelines from Europe and North America, a list of the critical factors and mechanisms contributing to GERD was compiled (4-7,13-23). These include hiatal anatomic changes, i.e., hiatal hernia, LES incompetence, TLESRs, esophageal acid exposure, insufficient esophageal motility (IEM), delayed gastric emptying (DGE), duodeno-gastro-esophageal reflux (DGER) and obesity.

The purpose of this study is to assess a large GERD patient population to achieve a quantitative determination of the different pathophysiologic factors contributing to the disease.

\section{Methods}

Our group managed and investigated patients with GERD at a tertiary referral center in Frankfurt/Germany for benign esophageal and gastric disorders. All patients with foregut symptoms, referred for establishment of a precise diagnosis and potential surgical treatment, underwent a history and physical examination, as well as standardized symptom questionnaires since 2003. In addition, all patients were evaluated in a surgical diagnostic gastrointestinalfunction laboratory.

For this analysis only patients with documented GERD by proven pathologic esophageal acid exposure were selected from a prospectively maintained databank for all investigated patients, who were all under PPI-therapy prior to the initial office visit. We excluded data from patients with prior anti-reflux operations, as well as patients with other esophageal disorders (i.e., achalasia, dysmotility), focusing on patients with a primary diagnosis of GERD without any previous interventions, as documented by positive $24 \mathrm{~h}-\mathrm{pH}$ monitoring test $(1,14)$. The study was approved by the hospital institutional review board (MKF-010/2010). All patients gave informed consent for study evaluation and diagnostic work-up, and investigations followed a defined study protocol. All procedures followed were in accordance with the ethical standards of the responsible committee on human experimentation (institutional and national) and with the Helsinki Declaration of 1964 and later versions.

Management of patients was performed by the same team over the complete study period. The patients were first evaluated by an experienced, board-certified surgeon to perform the clinical assessment and determine a diagnostic plan. Symptoms were evaluated with a standardized questionnaire measuring also symptom intensity with an analog scale from 0 (no symptoms) - 5 (maximum intensity). All patients had a measurement of their body mass index (BMI). All patients underwent an upper gastrointestinal endoscopy. Initially lesions detected in the esophagus were classified according to Savary and Miller, later this was revised to classification according to the Los Angeles classification system $(5,23,24)$. Hiatal hernia size was measured by vertical length, from the beginning of the gastric folds representing the cardia to the level of the crura as detected during endoscopy. Care was taken to perform these measurements at the beginning of the investigation prior to major air-insufflation of the stomach.

Quality of Life was evaluated in this study population by the Gastrointestinal Quality of Life Index (GIQLI), a wellestablished metric that is validated in several languages (25). The GIQLI carries five different components addressing quality of life, including core GI symptoms, psychological, physical, and social factors, disease-specific items, and influence of administered therapy with a maximum index points of 144 , evaluated by 36 questions.

All patients underwent esophageal manometry initially 


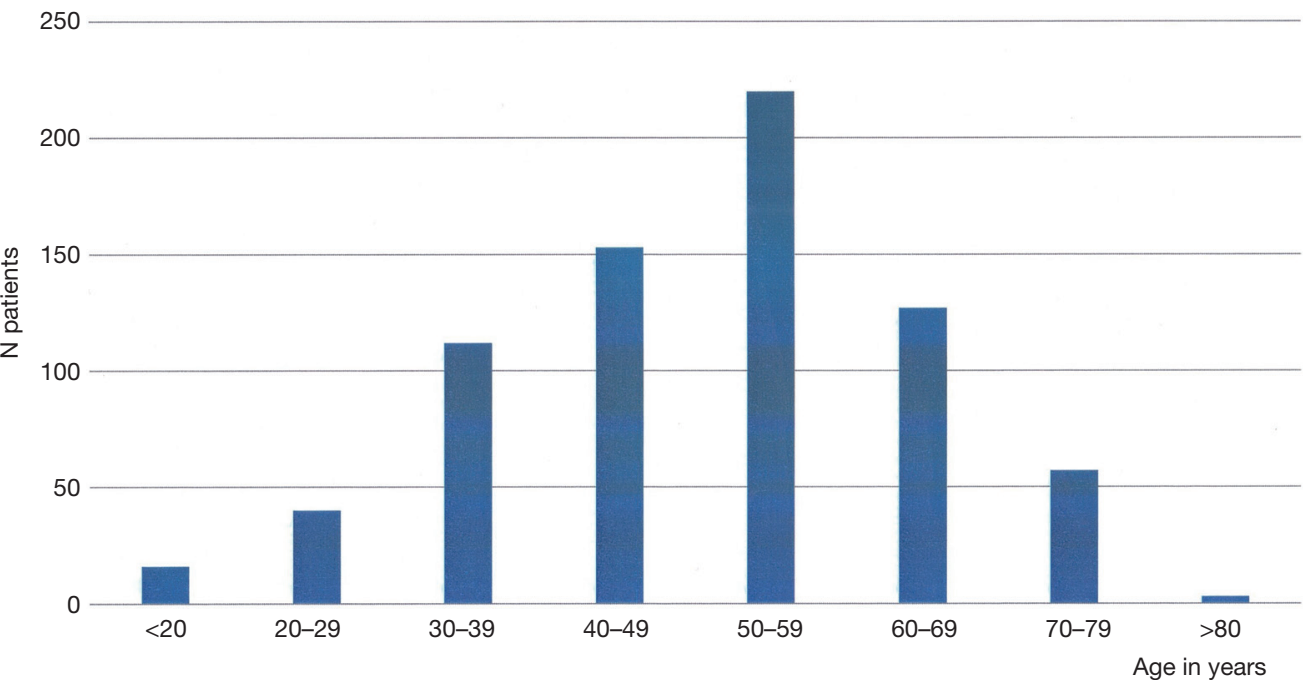

Figure 1 Age distribution among 728 patients with proven GERD as documented by pathologic esophageal acid exposure by 24 h-pHmonitoring. GERD, gastroesophageal reflux disease.

by perfusion manometry, since 2010 by high resolution manometry (HRM) to determine LES incompetence and the presence or absence of an esophageal motility disorder $(3,11,12,15,18,26)$.

The presence of pathologic reflux was evaluated by 24-h-pH-monitoring. In recent years impedance $\mathrm{pH}$ monitoring utilizing the standard position of the $\mathrm{pH}$ probe $5 \mathrm{~cm}$ above the upper border of the LES was used $(1,3,4)$. Impedance-pH-monitoring was performed using standard technique for analysis of the DeMeester score $(8-10,26)$. A DeMeester score above 14.7 signified pathologic esophageal acid exposure. The results of this investigation determined also the selection of the patients for this analysis. Seven days prior to the examination, all medications affecting motility and acid suppression were stopped. Bilirubin exposure as marker for DGER was measured with a photooptic assessment system (Bilitec ${ }^{\mathrm{TM}}$ ) and evaluated as published previously $(10,27)$.

Our goal was to investigate a representative population of GERD patients. Initially all patients with symptoms indicating a GERD presence were seen and investigated. For the analysis we focused on patients with documented GERD by positive pathologic acid exposure on 24-h $\mathrm{pH}$ monitoring. The intensity of symptoms was compared to the functional status of the patients such as incompetence of the LES and the extent of the esophageal acid exposure.

Statistical comparison with a t-test for unpaired samples was used for the comparison of data from the different samples. A Chi-square test was used for comparison of group data.

\section{Results}

\section{Patient characteristics}

More than 1,800 patients had been documented in the foregut database between 2003 and 2017. In total, 728 patients (420 males; 308 females) were selected for this analysis based on a documented presence of GERD by positive pathologic 24-h-pH-monitoring regarding the presence of pathophysiologic components of GERD and the availability of the data. Mean age was 49.9 years (range, 18-101 years). Figure 1 shows the age distribution in these patients. Table 1 provides on overview on the characteristics of the selected patients. The mean BMI in this GERDpatient population is $27.2 \mathrm{~kg} / \mathrm{m}^{2}$ (range, $20-45 \mathrm{~kg} / \mathrm{m}^{2}$ ). Figure 2 shows the distribution of BMI in the patient population, indicating that $26.6 \%$ of these patients have been obese.

Quality of Life as measured with the GIQLI is demonstrated in Figure 3. Different dimensions of the GIQLI such as gastrointestinal symptoms, emotional status, physical status, social status and influence of therapy are demonstrated. The values of the GERD study population are related to the maximal possible index values for the 5 
different dimensions, showing a mean overall GIQLI of 91 (range, 43-138; normal level: 121). Notably, Quality of Life of GERD patients in the study population was substantially decreased to normal patient metrics.

The presence of esophagitis is demonstrated in Figure 4. A substantial part (30.6\%) of these GERD patients did not show any evidence of esphagitis, however these patients were all under PPI-therapy. Minor esophagitis (SavaryMiller type 1 or Los Angeles Grade A) was documented in $22.4 \%$ of patients. More severe mucosal damage and/ or alterations were seen in almost $50 \%$ of GERD-patients

Table 1 Overview on the patients' characteristics

\begin{tabular}{lc}
\hline Variables & GERD-data \\
\hline $\mathrm{N}$ & 728 \\
Age (years), mean & 49.9 \\
BMI mean & 27.2 \\
Esophagitis (\% presence) & 69.4 \\
Hiatal hernia (\% presence) & 95.4 \\
GIQLI mean (normal: 121) & 92.9 \\
LES incompetence (\% presence) & 88.0 \\
Esophageal acid exposure & \\
Mean (normal: <14.7) & 53.9 \\
\% presence & 100 \\
\hline
\end{tabular}

GIQLI, gastrointestinal quality of life index. in this population (Figure 4). In 10\% an endoscopic and histologic evidence of Barrett's esophagus was documented.

\section{Results of pathophysiologic factors}

The analysis of 728 patients with primary GERD in a tertiary surgical referral unit shows as pathophysiologic factors and contributors of the disease the presence of hiatal hernias $(\mathrm{HH})$, the LES-incompetence, an IEM, delayed gastric emptying (DGE) and the presence of DGER. Figure 5 demonstrates an overview of the frequency of these different pathophysiologic components of GERD in our study population.

Most frequent factors are the presence of a hiatal hernia (95.4\%) as major anatomic alteration and the LESincompetence (too weak and/or too short LES) (88\%). The majority of GERD patients have a hiatal hernia measuring between 2-5 cm vertical length.

Another important factor is DGER, present in 55\% of these GERD patients, in patients with histologic and endoscopic evidence of Barrett's esophagus even 89\%.

DGE could be measured by Barium-Sandwich emptying radiography and/or gastric emptying scintigraphy in $6.8 \%$ of these patients. IEM was found in $8.8 \%$ of the patients, based on esophageal manometry.

Table 2 demonstrates the relationship between objective functional test results and the intensity of symptoms. The intensity of heartburn has been significantly different

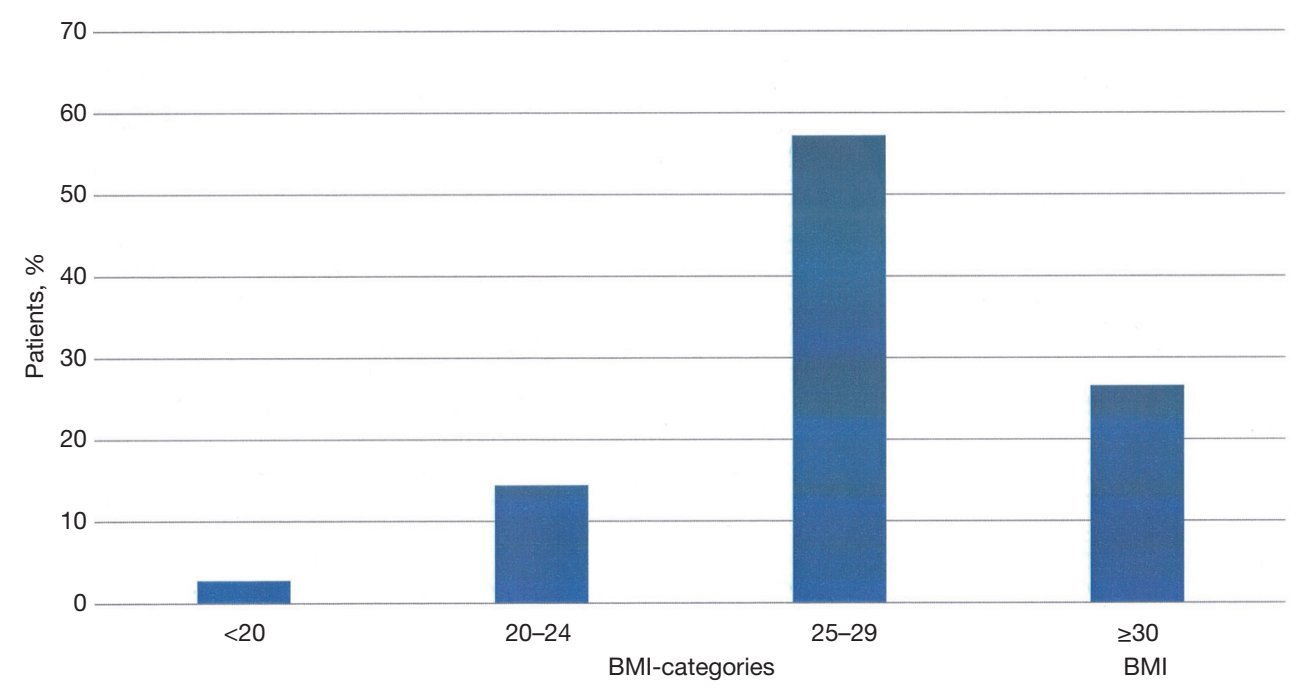

Figure 2 Distribution of body mass index assessment as marker of obesity in 728 GERD-patients in Frankfurt am Main, Germany. GERD, gastroesophageal reflux disease. 


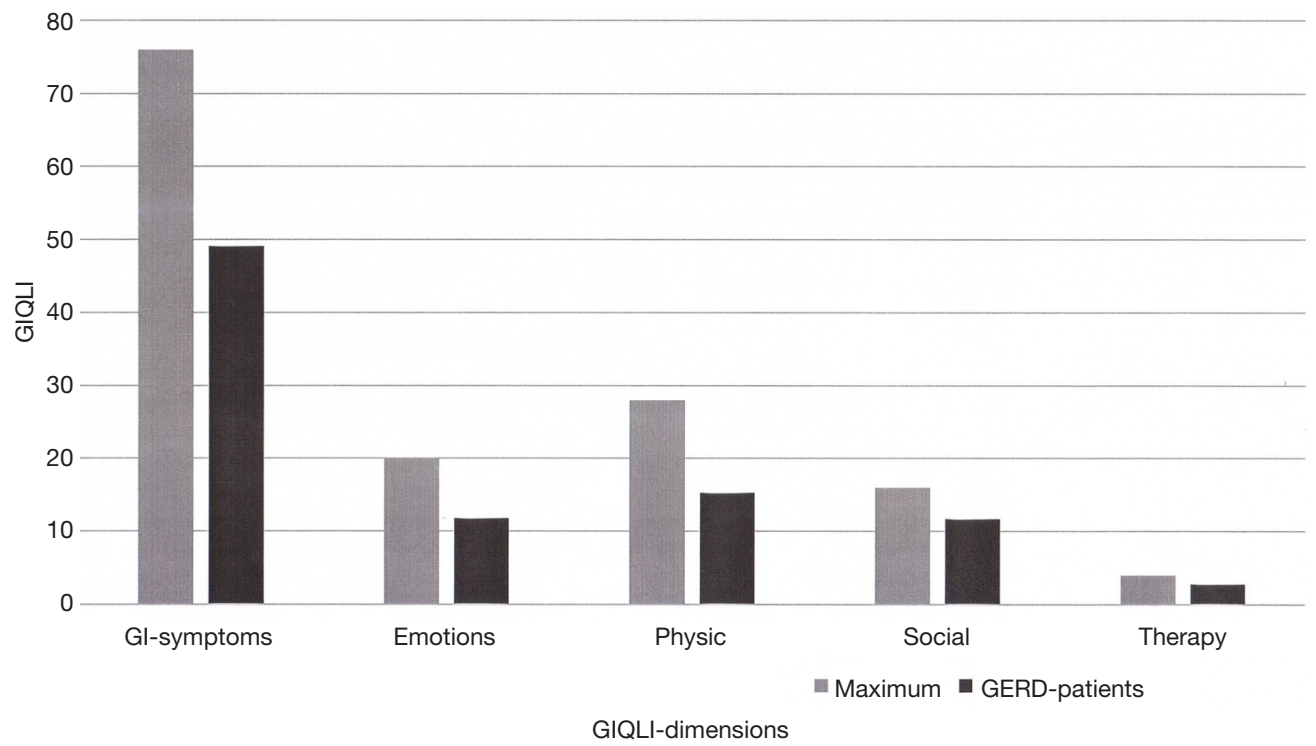

Figure 3 Distribution of quality of life, assessed in GERD-patients by GIQLI. Note the importance of gastrointestinal symptoms as well as physical sign among the different dimensions of the GIQLI. The GIQLI is substantially reduced in GERD-patients compared to values of a healthy control group. GERD, gastroesophageal reflux disease; GIQLI, gastrointestinal quality of life index.

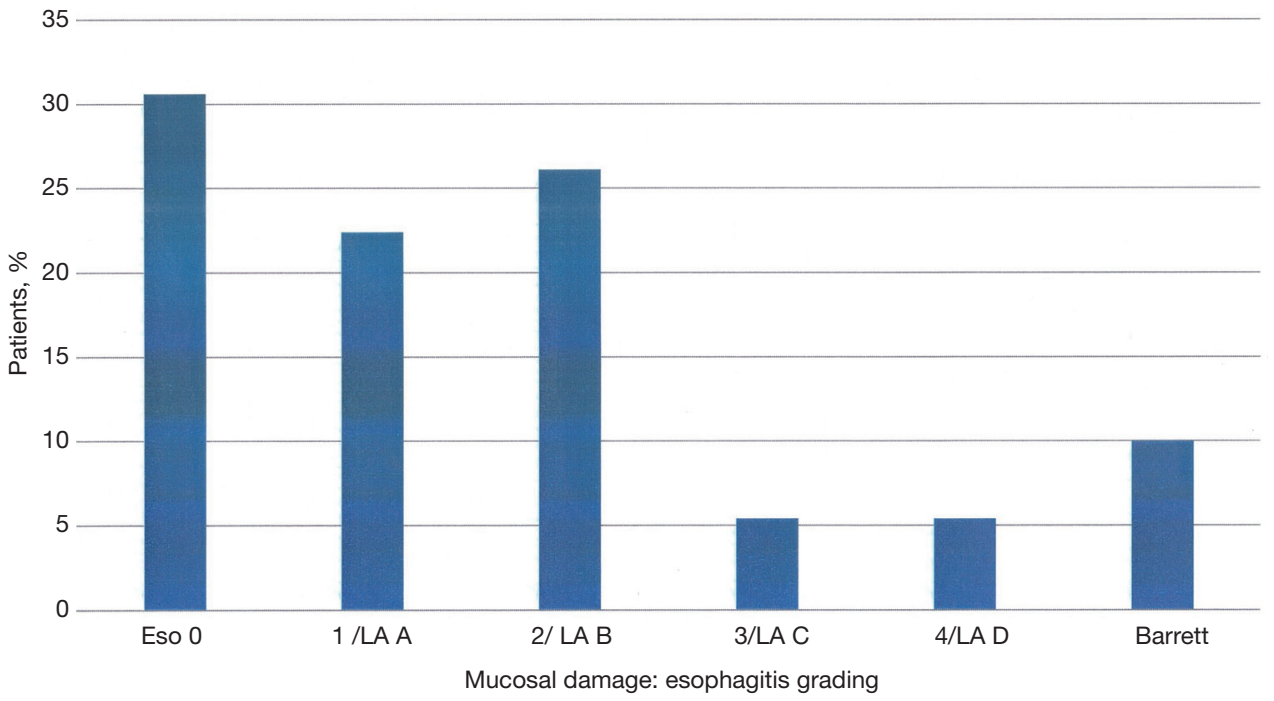

Figure 4 Distribution of the presence of esophagitis in 728 GERD-patients determined either by Savary-Miller classification [1-4] or by Los Angeles grading (A-D). Ten percent of patients do have endoscopic and histologic evidence of Barrett's esophagus. GERD, gastroesophageal reflux disease.

between patients with and those without LES incompetence (LES-I). The intensity scores are elevated for patients with incompetent sphincter ( 3.4 in patients with LES-I; 1.8 in patients without LES-I; $\mathrm{P}<0.0006)$. The differences in symptom intensity are also significant for regurgitation, however all other symptoms have no remarkable differences detected for changes in objective functional status.

In summary, presence a of hiatal hernia, a mechanically incompetent LES and the presence of duodenal juice contents in the esophageal lumen are the most frequent 


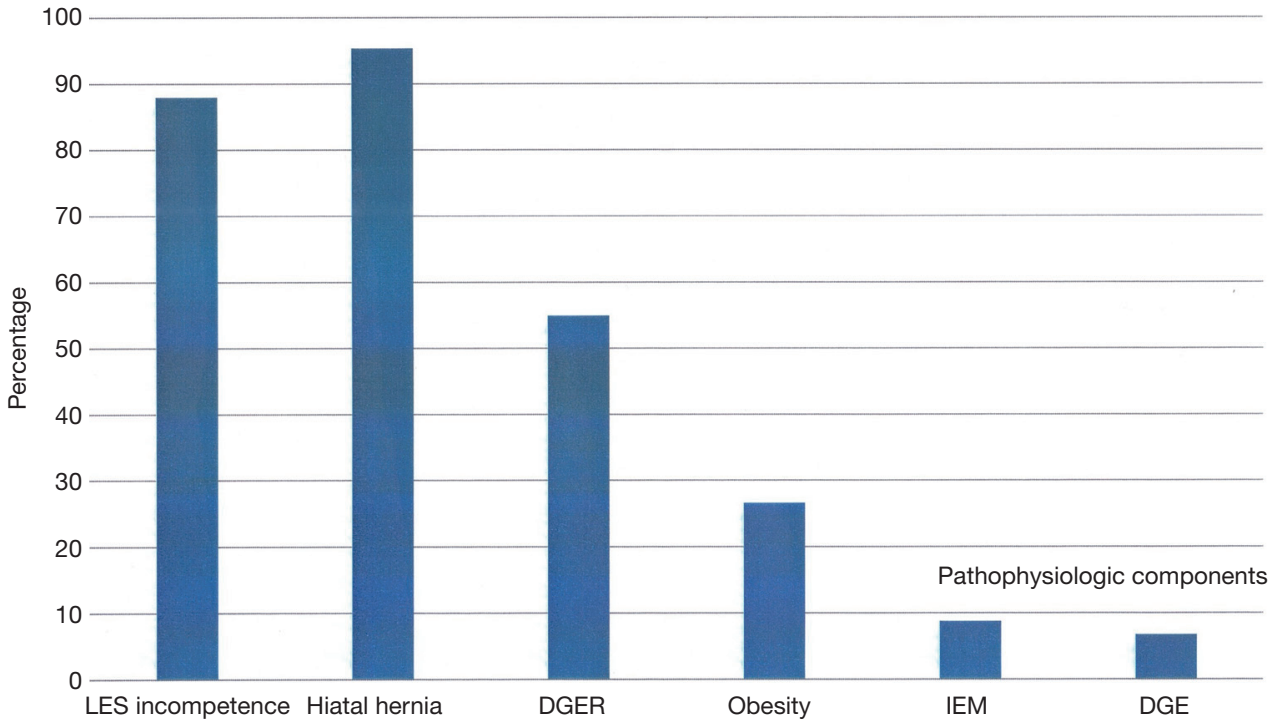

Figure 5 Overview on the presence of different pathophysiologic factors in this cohort of 728 GERD-patients as determined by extensive diagnostic investigations. HH 95.4\%; LES-incompetence 88\%, DGER 55\%, obesity 25.6\%, IEM 8.8\%, DGE 6.8\%. GERD, gastroesophageal reflux disease; HH, hiatal hernia; LES, lower esophageal sphincter; DGER, duodeno-gastro-esophageal reflux; IEM, impaired esophageal motility; DGE, delayed gastric emptying.

Table 2 Relation between symptom intensity [measured on analog scale from 0 (none) - 5 (maximum) and LES-incompetence]

\begin{tabular}{lccc}
\hline Symptom & LES competent & LES incompetent & P \\
\hline Heartburn & 1.8 & 3.4 & 0.0006 \\
Regurgitation & 1.4 & 2.7 & 0.003 \\
Retrosternal pain & 0.6 & 0.5 & $\mathrm{~ns}$ \\
Respiratory symptoms & 1.9 & 1.8 & $\mathrm{~ns}$ \\
Dysphagia & 0.8 & 0.9 & $\mathrm{~ns}$ \\
Epigastric pain & 2.1 & 2.2 & $\mathrm{~ns}$ \\
Nausea/vomiting & 0.5 & 1.2 & $\mathrm{~ns}$ \\
Fullness & 2.2 & 2.5 & $\mathrm{~ns}$ \\
Gas-related symptoms & 2.2 & 2.4 & $\mathrm{~ns}$ \\
\hline
\end{tabular}

LES, lower esophageal sphincter.

pathologic changes in GERD, followed by less frequent factors such as obesity, IEM, and DGE.

\section{Discussion}

The characteristics of our study population reflect a typical picture of GERD patients, with average age around the 4th and 5th decade of life, as previously reported in the literature (5-7). Patients with GERD exhibit a substantial reduction in their quality of life (28-32). When examining the contributing factors to overall quality of life, gastrointestinal symptoms and physical changes are the main drivers reducing quality of life, reflected in the GIQLI-data $(25,28,32)$. These two factors can influence the emotional component, which can further reduce the GIQLI score. This supports previous literature indicating that patients seek definitive interventional treatment after undergoing long-term medical management $(28,29,33,34)$. 
Table 3 Overview on the presence (percentage) of pathophysiologic factors in GERD in literature

\begin{tabular}{lcccccc}
\hline Author, year & LES & TLESR & HH & DGER & DGE & IEM \\
\hline DeMeester, 1992 & 91 & - & 82 & - & 33 & 16 \\
Fuchs, 1995 & 87 & - & 80 & 6 & 5 & 14 \\
Boeckxstaens, 2007 & 90 & 33 & 75 & - & $10-33$ & $25-48$ \\
Herbella, 2010 & High & 40 & 54 & - & - & $40-50$, severe 20 \\
Herregods, 2015 & High & Association with acid & - & 12 & Related & OR: 1,87 \\
\hline
\end{tabular}

LES, lower esophageal sphincter; TLESR, transient LES relaxation; HH, hiatal hernia; GERD, gastroesophageal reflux disease; DGE, delayed gastric emptying; IEM, impaired esophageal motility.

In addition to reduction in quality of life, psychological ability of patients to cope with the symptoms plays a significant role in their well-being $(31,35,36)$. GERD patients have a wide variety of symptoms along with substantial overlap with other disorders, thus symptomatology alone is difficult to use for diagnostic discrimination and/or patient selection for therapy (5,31,37-39).

Various pathophysiologic factors may contribute to both severity and the trajectory of reflux (2-7). GERD has been determined to be a multifactorial disorder (2-7). Prior publications highlight the different components, usually either providing an overview or focusing on a few detailed aspects of the pathophysiologic background of the disease (5-13,16-21). Table 3 demonstrates an insight regarding the main publications with overviews on the pathophysiologic background of GERD $(3,4,6,7,13)$. In the current analysis, we assessed a population of 728 GERD patients, permitting evaluation of all possible contributing factors in one population, thus allowing for comparison of the presence of different pathophysiologic components. Our results show that anatomical changes and malfunction of the cardia as the natural antireflux barrier are the most frequent functional defects detected.

The anatomic changes after pathologic deterioration of cardia fixation in the hiatal aperture by the phrenoesophageal membrane, with subsequent development of hiatal hernia are frequent, if not critical in precipitating the development of GERD $(5,6,14,20,23,26)$. Our study shows that most hernias measure in the $2-5 \mathrm{~cm}$ range of vertical extension between the cardia and crura; this dimension may reflect the time period from initial symptoms to diagnostic workup in recent years.

The weakness of the natural antireflux barrier at the cardia obviously plays an important role in the pathophysiology of GERD $(2-7,14,26)$. As published in multiple studies, LES-incompetence either via decreased intraabdominal length, overall shortening of LES-length, and/or decreased LES-pressure, has been demonstrated in severe GERD (2-7,13,14,18-20). In our analysis, LES incompetence is present in $88 \%$ of the investigated patients and is therefore a major component. Other reports have analysed transient LES-relaxations as major factor of pathologic reflux, which is discussed controversially between surgeons and gastroenterologists $(6,14,17-19,40-47)$. Fact is, that the malfunction of the anatomical and functional components of the antireflux barrier plays a major role in allowing for pathologic gastroesophageal reflux $(6,14,40-42)$.

Another controversial discussion has developed around reflux of duodenal and enteric contents into the esophagus. Duodenal refluxate can be quite harmful to the esophageal mucosa $(3,4,10,14,27,48-52)$. Studies of patients diagnosed with Barrett's esophagus indicated that the refluxate is composed of duodenal contents, highlighting both the presence and effect of DGER $(10,14,48-52)$. We investigated this subset of subjects with the Bilitec ${ }^{\mathrm{TM}}$ bilirubin monitoring device. Our findings support the contribution of DGER to the pathophysiology of GERD, particularly in Barrett patients $(10,14,48-52)$. The implications may play a role in the progression of GERD and Barrett's esophagus (50-52).

IEM has been investigated in GERD-patients (3-7). The prevalence of IEM in these patients is reported between $10-50 \%(3,4,6,53-57)$. In a previous study from our group we found $14 \%$ of GERD patients to have IEM (4). However, an isolated pathophysiologic defect is was found in $2 \%$ (4). In the present study, we documented IEM in $8.8 \%$ of the GERD study population, indicating that the majority of GERD-patients do not develop a severe, detectable IEM.

Other factors involved in the development of GERD are less common, such as DGE causing stasis of gastric contents, ultimately leading to reflux. In the literature, DGE is present in GERD in 5-33\%, while in this study we detected it in $6.8 \%$ of patients $(6,16,21,58)$. 
Obesity, defined as a body mass index greater than or equal to 30 is associated with an increased prevalence of GERD as compared to the non-obese patient population (59-62). A variety of explanations for increased frequency of GERD with increasing weight have been proposed (4,59-62). Obesity can cause increased esophageal acid exposure with increased chance of reflux (61). Studies showed a statistically significant inverse relationship between BMI and LES pressure (61). Our subjects had a mean BMI of 27 , with only $15.8 \%$ of patients falling in the category of BMI $>30$; this may explain the apparent lesser contribution of obesity to GERD in our patients.

In conclusion, in our evaluation of GERD patients referred for surgical intervention, the most important pathophysiologic component in severe GERD, appears to be mechanical incompetence and anatomical alterations of the anti-reflux barrier. These results emphasize the necessity of mechanical augmentation of the LES in successful longterm therapy for severe GERD.

\section{Acknowledgments}

Funding: None.

\section{Footnote}

Conflicts of Interest: All authors have completed the ICMJE uniform disclosure form (available at http://dx.doi. org/10.21037/tgh.2020.02.12). SH reports other from stock option from Torax medical, outside the submitted work. The other authors have no conflicts of interest to declare.

Ethical Statement: The authors are accountable for all aspects of the work in ensuring that questions related to the accuracy or integrity of any part of the work are appropriately investigated and resolved. The study was approved by the hospital institutional review board. All patients gave informed consent for study evaluation and diagnostic work-up, and investigations followed a defined study protocol. All procedures followed were in accordance with the ethical standards of the responsible committee on human experimentation (institutional and national) and with the Helsinki Declaration of 1964 and later versions.

Open Access Statement: This is an Open Access article distributed in accordance with the Creative Commons Attribution-NonCommercial-NoDerivs 4.0 International License (CC BY-NC-ND 4.0), which permits the non- commercial replication and distribution of the article with the strict proviso that no changes or edits are made and the original work is properly cited (including links to both the formal publication through the relevant DOI and the license). See: https://creativecommons.org/licenses/by-nc-nd/4.0/.

\section{References}

1. Johnson LF, DeMeester TR. Twenty-four-hour $\mathrm{pH}$ monitoring of the distal esophagus. A quantitative measure of gastroesophageal reflux. Am J Gastroenterol 1974;62:325-332.

2. Skinner DB. Pathophysiology of gastroesophageal reflux. Ann Surg 1985;202:546-56.

3. DeMeester TR. Definition, detection and pathophysiology of gastro-esophageal reflux disease. In: DeMeester TR, Matthews HR. editors. International trends in general thoracic surgery, vol.3 ed. Benign esophageal disease. St. Louis: Mosby, 1987;99-127.

4. Fuchs KH, Freys SM, Heimbucher J, et al. Pathophysiologic spectrum in patients with gastroesophageal reflux disease in a surgical GI function laboratory. Diseases of the Esophagus 1995;8:211-7.

5. Vakil N, van Zanten SV, Kahrilas PJ, et al. The Montreal Definition and Classification of GERD: a global Evidencebased Consensus. Am J Gastroenterol 2006;101:1900-20.

6. Boeckxstaens GEE. Review: the pathophysiology of gastro-esophageal reflux disease; Aliment Pharmacol Ther 2007;26:149-60.

7. Herbella FA, Patti MG. Gastroesophageal Reflux Disease: From pathophysiology to treatment. World J Gastroenterol 2010;16:3745-9.

8. Shay S. Esophageal impedance monitoring: the ups and downs of a new test. Am J Gastroenterol 2004;99:1020-2.

9. Zerbib F, des Varannes SB, Roman S, et al. Normal values and dayto-day variability of 24-h ambulatory oesophageal impedance-pH monitoring in a Belgian French cohort of healthy subjects. Aliment Pharmacol Ther 2005;22:1011-21.

10. Fein M, Maroske J, Fuchs KH. Importance of duodenogastric reflux in gastro-oesophageal reflux disease. Br J Surg 2006;93:1475-82.

11. Pandolfino JE, Fox MR, Bredenoord AJ, et al. High resolution manometry in clinical practice: utilizing pressure topography to classify esophageal motility abnormalities. Neurogastroenterol Motil 2009;21:796-806.

12. Bredenoord AJ, Fox MR, Kahrilas PJ, et al. Chicago Classification Criteria of esophageal motility disorders 
defined in high resolution esophageal pressure topography (EPT). Neurogastroenterol Motil 2012;24:57-65.

13. Herregods TVK, Bredenoord AJ, Smout AJPM. Pathophysiology of GERD: new understanding in a new era. Neurogastroenterol Motil 2015;27:1202-13.

14. DeMeester TR. Etiology and Natural History of Gastroesophageal Reflux Disease and Predictors of progressive Disease. In: Yeo CJ, DeMeester SR, McFadden DW. editors. Shackelford's Surgery of the Alimentary Tract. 8th ed. Philadelphia: Elsevier, 2019;204-20.

15. Kahrilas PJ, Bredenoord AJ, Fox MR, et al. The Chicago Classification of esophageal motility disorders, v3.0. Neurogastroenterol Motil 2015;27:160-74.

16. Schwizer W, Hinder RA, DeMeester TR. Does delayed gastric emptying contribute to gastroesophageal reflux disease? Am J Surg 1989;157:74 81.

17. Dent J, Holloway RH, Toouli J, et al. Mechanisms of lower oesophageal sphincter incompetence in patients with symptomatic gastro-oesophageal reflux. Gut 1988;29:1020-8.

18. Zaninotto G, DeMeester TR, Schwizer W, et al. The lower esophageal sphincter in health and disease. Am J Surg 1988;155:104 11.

19. Mittal RK, Holloway RH, Penagini R, Blackshaw A, Dent J: Transient lower esophageal sphincter relaxations. Gastroenterology 1995;109:601-10.

20. Fein M, Ritter M, DeMeester TR, et al. Role of lower esophageal sphincter and hiatal hernia in the pathogenesis of GERD. J Gastrointest Surg 1999;3:405-10.

21. Buckles DC, Sarosiek I, McMillin C, et al. Delayed gastric emptying in gastroesophageal reflux disease: reassessment with new methods and symptomatic correlations. Am J Med Sci 2004;327:1-4.

22. Fuchs KH, Breithaupt W, Varga G, Schulz T, Babic B. Management of delayed gastric emptying. UEGW, 2015; Abstract.

23. Fuchs KH, Babic B, Breithaupt W, Dallemagne B, Fingerhut A, Furnee E, Granderath F, Horvath OP, Kardos P, Pointner R, Savarino E, Van HeerwardenLindeboom M, Zaninotto G. EAES recommendations for the management of Gastroesophageal reflux Disease. Surg Endosc 2014;28:1753-73.

24. Lundell LR, Dent J, Bennett JR, et al. Endoscopic assessment of oesophagitis: clinical and functional correlates and further validation of the Los Angeles classification. Gut 1999;45:172-80.

25. Eypasch E, Williams JI, Wood-Dauphinee S, et al. Gastrointestinal Quality of Life Index: development, validation and application of a new instrument. Br J Surg 1995;82:216-22.

26. Jobe BA, Richter JE, Hoppo T, et al. Preoperative diagnostic workup before antireflux surgery: an evidence and experience-based consensus of the Esophageal Diagnostic Advisory Panel. J Am Coll Surg 2013;217:586-97.

27. Fein M, Fuchs KH, Bohrer T, et al. Fiberoptic technique for 24-hour bile reflux monitoring. Standards and normal values for gastric monitoring. Dig Dis Sci 1996;41:216-25.

28. Kamolz T, Granderath, Pointner R. Laparoscopic antireflux surgery: disease-related quality of life assessment before and after surgery in GERD patients with and without Barrett's esophagus. Surg Endosc 2003;17:880-5.

29. Dallemagne B, Weertz J, Markiewicz S, et al. Clinical results of laparoscopic fundoplication ten years after surgery. Surg Endosc 2006;20:159-65.

30. Labenz J, Labenz G, Stephan D, et al. Insufficient symptom control under long-term treatment with PPI in GERD - fact or fiction? MMW Fortschr Med 2016;158 Suppl 4:7-11.

31. Fuchs KH, Musial F, Ulbricht F, et al. Foregut symptoms, somatoform tendencies, and the selection of patients for antireflux surgery. Dis Esophagus 2017;30:1-10.

32. Fuchs HF, Babic B, Fuchs KH, et al. Do patients with gastroesophageal reflux disease and somatoform tendencies benefit from antireflux surgery? World J Gastroenterol 2019;25:388-397.

33. Zaninotto G, Portale G, Costantini M, et al. Longterm results (6-10 years) of laparoscopic fundoplication.J Gastrointest Surg 2007;11:1138-45.

34. Lord RVN, DeMeester SR, Peters JH, et al. Hiatal Hernia, Lower Esophageal Sphincter Incompetence, and Effectiveness of Nissen Fundoplication in the Spectrum of Gastroesophageal Reflux Disease; J Gastrointest Surg 2009;13:602-10.

35. Tack J, Caenepeel P, Arts J, et al. Prevalence of acid reflux functional dyspepsia and its association with symptom profile. Gut 2005;54:1370-6.

36. Savarino E, Pohl D, Zentilin P, et al. Functional heartburn has more in common with functional dyspepsia than with non-erosive reflux disease. Gut 2009;58:1185-91.

37. Klauser AG, Schindlbeck NE, Müller-Lissner SA. Symptoms in gastro-esophageal reflux disease. Lancet 1990;335:205-8.

38. Costantini M, Crookes PF, Bremner RM, et al. Value of physiologic assessment of foregut symptoms in a surgical practice. Surgery 1993;114:780-6.

39. Broderick R, Fuchs KH, Breithaupt W, et al. Clinical 
Presentation of GERD: A Prospective Study on Symptom Diversity and Modification of Questionnaire Application. Dig Dis 2020;38:188-95.

40. Mittal RK, McCallum RW. Characteristics and frequency of transient relaxations of the LES in patients with reflux esophagitis. Gastroenterology 1988;95:593-9.

41. Holloway RH, Kocyan P, Dent J. Provocation of transient lower esophageal sphincter relaxations by meals in patients with symptomatic gastroesophageal reflux. Dig Dis Sci 1991;36:1034-9.

42. Schoeman MN, Tippett MD, Akkermans LM, et al. Mechanisms of gastroesophageal reflux in ambulant healthy human subjects. Gastroenterology 1995;108:83-91.

43. van Herwaarden MA, Samson M, Smout AJP. Excess gastroesophageal reflux in patients with hiatal hernia is caused by mechanisms other than transient LES relaxations. Gastroenterology 2000;119:1439.

44. Trudgill NJ, Riley SA. Transient lower esophageal sphincter relaxations are no more frequent in patients with gastroesophageal reflux disease than in asymptomatic volunteers. Am J Gastroenterol 2001;96:2569-74.

45. Ayazi S, Hagen JA, Zehetner J, et al. The value of highresolution manometry in the assessment of the resting characteristics of the lower esophageal sphincter. J Gastrointest Surg 2009;13:2113-20.

46. Ayazi S, Tamhankar A, DeMeester SR, et al. The impact of gastric distension on the lower esophageal sphincter and its exposure to acid gastric juice. Ann Surg 2010;252:57-62.

47. Fuchs KH, Babic B, Fuchs HF. The esophageal sphincters in Health and Disease. In: Shackelford textbook "Surgery of the Alimentary tract" Eds Yeo CJ, Matthews JB, McFadden DW, Pemberton JH, Peters JH. 2019, 8th Edition, 2-10.

48. Fein M, Ireland AP, Ritter MP, et al. Duodenogastric reflux potentiates the injurious effects of gastroesophageal reflux. J Gastrointest Surg 1997;1:27-32; discussion 33.

49. Oberg S, Ritter MP, Crookes PF, et al. Gastroesophageal reflux disease and mucosal injury with emphasis on shortsegment Barrett's esophagus and duodenogastroesophageal reflux. J Gastrointest Surg 1998;2:547-53; discussion 553-4.

50. Chandrasoma PT, Lokuhetty DM, DeMeester TR, et al. Definition of histopathologic changes in GERD. Am J Surg Pathol 2000;24:344-51.

51. Theisen J, Peters JH, Fein M, et al. The mutagenic potential of duodenoesophageal reflux. Ann Surg 2005;241:63-8.
52. Labenz J, Chandrasoma PT, Knapp LJ, et al. Proposed approach to the challenging management of progressive gastroesophageal reflux disease. World J Gastrointest Endosc 2018;10:175-83.

53. Diener U, Patti MG, Molena D, et al. Esophageal dysmotility and gastroesophageal reflux disease. J Gastrointest Surg 2001;5:260-5.

54. Fibbe C, Layer P, Keller J, et al. Esophageal motility in reflux disease before and after fundoplication: a prospective, randomized, clinical, and manometric study. Gastroenterology 2001;121:5-14.

55. Xenos ES. The role of esophageal motility and hiatal hernia in esophageal exposure to acid. Surg Endosc 2002;16:914-20.

56. Patti MG, Gasper WJ, Fisichella PM, et al. GERD and connective tissue disorders: pathophysiology and implications for treatment. J Gastrointest Surg 2008;12:1900-6.

57. Fuchs HF, Gutschow CA, Brinkmann S, et al. Effect of laparoscopic antireflux surgery on esophageal motility. Dig Surg 2014;31:354-8.

58. Penagini R, Bravi I. The role of delayed gastric emptying and impaired oesophageal body motility. Best Pract Res Clin Gastroenterol 2010;24:831-45.

59. El-Serag HB, Graham DY, Satia JA, et al. Obesity is an independent risk factor for GERD symptoms and erosive esophagitis. Am J Gastroenterol 2005;100:1243-50.

60. Jacobson BC, Somers SC, Fuchs CS, et al. Body-Mass Index and Symptoms of Gastroesophageal Reflux in Women. N Engl J Med 2006;354:2340-8.

61. Ayazi S, Hagen JA, Chan LS, et al. Obesity and gastroesophageal reflux: quantifying the association between body mass index, esophageal acid exposure, and lower esophageal sphincter status in a large series of patients with reflux symptoms.J Gastrointest Surg 2009;13:1440-7.

62. Nadaleto BF, Herbella FA, Patti MG. Gastroesophageal reflux disease in the obese: Pathophysiology and treatment. Surgery 2016;159:475-86.

doi: $10.21037 / \operatorname{tgh} .2020 .02 .12$

Cite this article as: Fuchs KH, Lee AM, Breithaupt W, Varga G, Babic B, Horgan S. Pathophysiology of gastroesophageal reflux disease-which factors are important? Transl Gastroenterol Hepatol 2021;6:53. 